Original Research Paper

\title{
Impact of Acute Bronchiolitis on Cardiac Functions and Serum microRNA-122 and 499
}

\author{
${ }^{1}$ Mona Abd El-Gelel Mohamed and ${ }^{2}$ Khalid Mahmoud Zayed \\ ${ }^{1}$ Biochemistry Division, Department of Chemistry, Faculty of Science, Al-Azhar University, Cairo, Egypt \\ ${ }^{2}$ Department of Pediatric, Faculty of Medicine, Al-Azhar University, Cairo, Egypt
}

\author{
Article history \\ Received: 30-10-2015 \\ Revised: 25-11-2015 \\ Accepted: 25-01-2016 \\ Corresponding Author: \\ Mona Abd El-Gelel Mohamed \\ Biochemistry Division, \\ Department of Chemistry, \\ Faculty of Science, Al-Azhar \\ University, Cairo, Egypt \\ Email: mabdelgelel@gmail.com
}

\begin{abstract}
Bronchiolitis is an acute inflammatory injury of the bronchioles that is usually caused by a viral infection, most commonly Respiratory Syncytial Virus (RSV). This study aimed to verify the direct injurious effect of acute bronchiolitis on the myocardium and serum level of microRNA-122 and 499 (miR-122 and miR-499) of infected infants. Serum lactate dehydrogenase (LDH), creatine phosphokinase-isoenzyme MB (CK$\mathrm{MB}$ ) and cardiac troponin I (cTp I) were significantly elevated in mild to moderate group as well as severe group except cTp I which showed nonsignificant elevation in mild to moderate group, compared to control group. Quantitative Reverse Transcriptase Polymerase Chain Reaction (qRT-PCR) was carried out to evaluate the serum level of miR-122 and miR-499. Sharp elevation in serum miR-122 was observed in severe cases, while miR-499 was statistically non-significant as compared to both normal and mild to moderate groups. The flow velocities across the pulmonary, tricuspid and mitral valves were recorded using standard echocardiographic techniques. Echocardiographic data showed significant reduction in pulmonary At/Et ratio in severe bronchiolitis group, compared to both normal and mild to moderate groups, respectively. Parallel reduction was also observed in tricuspid and mitral E/A ratios, compared to both normal and mild to moderate groups, respectively. Severe bronchiolitis causes cardiac dysfunction due to hypoxia, cardiac strain and pulmonary hypertension in addition to up-regulation of serum miRNA- 122 .
\end{abstract}

Keywords: Acute Bronchiolitis, Cardiac Troponin I, microRNA-122

\section{Introduction}

Bronchiolitis "is a seasonal viral illness, characterized by fever, nasal discharge and dry, wheezy cough. On examination, there are fine inspiratory crackles and/or high-pitched expiratory wheeze" (Lakhanpaul et al., 2009). This is most commonly caused by Respiratory Syncytial Virus (RSV) which is the major respiratory pathogen in young children $(<1$ year of age) and virtually every individual has been infected with RSV at least once by the age of 3 (Bruce and Alcorn, 2011). The virus is a member of the Paramyxoviridae family, with a single-stranded, negative-sense RNA genome (Brock et al., 2003). It replicates in nasopharyngeal epithelium and then spreads to lower respiratory tract one to three days later (Thorburn and Hart, 2006). Together with influenza virus, RSV is also the most common cause for admissions in adults with chronic cardiac and pulmonary disorders and acute respiratory failure (Carrat et al., 2006). The importance of extrapulmonary manifestations of RSV infection has become evident (Eisenhut, 2006). Although the most frequent extra-pulmonary manifestations of RSV infection involve the cardiovascular system, the reasons leading to heart involvement during RSV infection are not fully known (Esposito et al., 2010).

MicroRNAs (miRNAs) are endogenous, singlestranded, 22-nucleotide non-coding RNAs. Individual miRNAs modulate the expression of collections of mRNA targets that often have related functions, thereby governing complex biological processes. MiRNAs are generally regarded as negative regulators of gene expression through inhibition of translation and/or promotion of mRNA degradation by basepairing to complementary sequences within the 3'Untranslated Region (3'UTR) of protein-coding mRNA transcripts (Humphreys et al., 2005; Small and Olson, 2011). Many miRNAs exhibit a tissue-specific 
distribution and they appear to play a key role in cell function both under physiological and pathological conditions. The wide ranging functions of microRNAs in the cardiovascular system have provided new perspectives on disease mechanisms and have revealed intriguing therapeutic targets, as well as diagnostics, for a variety of cardiovascular disorders (Small and Olson, 2011). The observation that miRNAs are stable and present in the circulation has led to a rapidly growing number of reports on the use of these molecules as biomarkers for various diseases, for example plasma concentration of miRNA-499 is a useful biomarker of myocardial injury in humans (Esposito et al., 2010; Gidlöf et al., 2011).

The objective of this study was to verify the direct injurious effect of acute bronchiolitis on the myocardium of affected infants and on serum level of miRNA-122 and 499 (miR-122 and miR-499).

\section{Subjects and Methods}

\section{Study Design}

This study was carried out at the Department of Pediatric, Al-Hussin University hospital, Egypt, during the winter season 2012-2013. Written informed consent to study participation was obtained from the patients' parents or legal guardians who were well informed in advance about the purpose of the study.

The study involved 26 infants aged 1-9 months who were admitted with acute bronchiolitis. The exclusion criteria were the presence of a chronic disease increasing the risk of complications of respiratory infection, including chronic disorders of the pulmonary or cardiovascular system, chronic metabolic disease, neoplasms, kidney or liver dysfunction, hemoglobinopathies, immunosuppression and genetic or neurological disorders.

The control group (con) consists of 13 apparently healthy children. None of these children were admitted to the pediatric intensive care unit and none were diagnosed with acute bronchiolitis.

Upon admission, the infants' demographic characteristics and medical history were systematically recorded using standardized written questionnaires and, after a complete physical examination, the infants with a diagnosis of acute bronchiolitis based on wellestablished criteria (Crowe, 2011) were enrolled. The severity of the disease was defined on the basis of a global evaluation of the signs and symptoms. In particular, on the basis of previously published criteria (Scarfone, 2005), respiratory illness was considered severe in the presence of all of $\leq 92 \%$ pulse oximetry, a respiratory rate of $\geq 60$ breaths/min, marked accessory muscle use, nasal flare or grunting, an inability to feed and a cyanotic appearance.
Consequently, infants with acute bronchiolitis were divided into two groups (13 patients each): Infants with mild to moderate bronchiolitis (mild and moderate) group and infants with severe bronchiolitis (severe) group.

\section{Hematological and Biochemical Studies}

Venous blood samples were obtained at the time of admission. A part of blood sample was taken on EDTA as whole blood sample for Complete Blood Counting (CBC) and blood gas analysis. Another part was taken in a plain tube without any anticoagulant for separation of serum by centrifugation at 3000 r.p.m for $10 \mathrm{~min}$ and then stored at $-70^{\circ} \mathrm{C}$.

Blood cell counting was carried out by cell counter fully automated (sysmex, Japan). Blood gases were estimated by blood gases and electrolyte analyzer (GEM premier 3000, USA). C-Reactive Protein (CRP) was measured using semi-quantitative CRP latex test kit (Plasmatec, UK) to eliminate bacterial infection. To evaluate myocardial function, serum creatine phosphokinase-isoenzyme $\mathrm{MB}$ (CK-MB) and lactate dehydrogenase (LDH) were assessed using colorimetric assay (Abcam, USA) and cardiac troponin I (cTp I) concentration was measured using immunoenzymatic assay (Accubind, USA) according to the manufacturer's instructions.

\section{$q R T-P C R$}

Quantitative Reverse Transcriptase Polymerase Chain Reaction (qRT-PCR) methodologies have been widely applied to miRNA research, especially in assessing the low level of certain serum miRNAs. Therefore, this system was applied to the present study to determine the circulating levels of miRNA-122 and 499. Total RNA was extracted from serum according to the method of Bravo et al. (2007), using high pure miRNA isolation kit (Roche Diagnostics, Switzerland). Reverse transcription was performed using the Transcript or First Strand cDNA Synthesis Kit (Roche Diagnostics). Primer sequences for each miRNA and control gene (Glyceraldehyde-3-phosphate dehydrogenase (GAPDH) are listed in Table 1 (primers were designed and provided by TIB MOLBIOL (Berlin, Germany). cDNA was amplified through PCR using Light Cycler Fast Start DNA Master Plus SYBR Green I (Roche Diagnostics). PCR was performed at $95^{\circ} \mathrm{C}$ for 10 min followed by 45 cycles of denaturation at $95^{\circ} \mathrm{C}$ for $10 \mathrm{sec}$, annealing (primer dependent) for 60 sec and extension at $72^{\circ} \mathrm{C}$ for $20 \mathrm{sec}$.

\section{Echocardiographic Studies}

The echocardiographic studies were made using a real time ultrasound imaging system (GE Vivid 3, China) equipped with 5 and $8 \mathrm{MHz}$ transducers. The 
echocardiographic measurements were made using standard techniques. M-mode measurements were made in accordance with the recommendations of the Committee of M-Mode Standardization of the American Society of Echocardiography. The flow velocities across the pulmonary, tricuspid and mitral valves were recorded from standard pericordial position using pulsed-wave Doppler. Pulmonary arterial blood pressure was assessed by measuring At/Et ratio, where At is the pulmonary acceleration time and Et is the pulmonary ejection time. Right ventricular diastolic function was assessed by measuring tricuspid E/A ratio, where $\mathrm{E}$ and $\mathrm{A}$ denote early and late tricuspid flow, respectively (Fig. 1). Left ventricular diastolic function was assessed by measuring mitral $\mathrm{E} / \mathrm{A}$ ratio where $\mathrm{E}$ and A denote early and late mitral flow, respectively. Systolic left ventricular function was assessed by determining the Fractional Shortening (FS) and Ejection Fraction (EF) (Gadish et al., 2010). Interpretations of these studies were performed an attending cardiologist blinded as to the cTp I and miRNAs results.

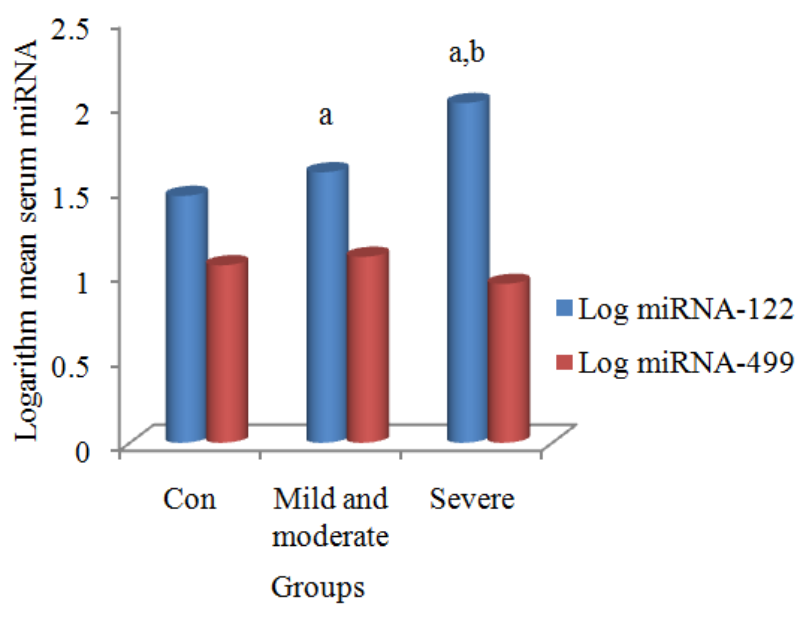

Fig. 1. Logarithm of mean of serum microRNA-122 and 499 in control and patient groups a: Significance Vs control group. b: Significance Vs mild and moderate group

Table 1. Primer sequences

\begin{tabular}{ll}
\hline miRNA-122 & Forward: \\
& 5' UGGAGUGUGACAAUGGUGUUUG 3' \\
& Reverse: \\
& 5' AACGCCAUUAUCACACUAAAUA 3' \\
miRNA-499 & Forward: \\
& 5' CGGCTGTTAAGACTTGCAGTG 3' \\
& Reverse: \\
& 5' GGGAAGCAGCACAGACTTG 3' \\
GAPDH & Forward: \\
(Oll et al., 2012) & 5' CCCCGGTTCTATAAATTGAGC 3' \\
& Reverse: \\
& 5' CACCTTCCCCATGGTGTCT 3'
\end{tabular}

\section{Statistical Analysis}

All results were expressed as the mean \pm Standard Error (SE). Statistical analysis was performed using Statistical Package for the Social Science for Windows (SPSS, version 16.0, Chicago, IL, USA). The data were analyzed by one-way Analysis Of Variance (ANOVA). To compare the difference among the groups, post hoc testing was performed by LSD test. Pearson's correlation analysis was used to determine the correlation among the parameters assessed. The $\mathrm{p}$-value $<0.05$ was considered statistically significant.

\section{Results}

Table 2 illustrates that severe bronchiolitis caused significant increase in respiratory and heart rates $(p<0.0001)$ in addition to the remarkable cyanosis and irritability as compared to normal children. In severe cases, levels of $\mathrm{pH}, \mathrm{pO}_{2}, \mathrm{HCO}_{3}$ and $\mathrm{O}_{2}$ saturation percent were significantly decreased $(\mathrm{p}<0.0001)$, while $\mathrm{pCO}_{2}$ was increased as compared to normal group. Nonsignificant differences were observed in blood hemoglobin concentration, RBCs count and serum CRP level in both patient groups, compared to normal control. In spite of the significant reductions $(p<0.001$ and 0.0001 , respectively) recorded in total WBCs count in both patient groups, lymphocytes showed significant elevations $(p<0.0001)$ in both mild and moderate and severe cases as compared to control group. On the other hand, serum biochemical markers of cardiac function (LDH, CK-MB and cTp I) were significantly elevated in both patient groups except cTp I which showed nonsignificant elevation in mild and moderate group, compared to control group. Multiple comparison analysis revealed that severe bronchiolitis caused significant elevation in respiratory and heart rates, lymphocyte percent, $\mathrm{pCO}_{2}, \mathrm{LDH}$ and $\mathrm{CK}-\mathrm{MB}$ levels as compared to mild and moderate group. Moreover, significant reductions in platelet count, $\mathrm{pH}, \mathrm{pO}_{2}$ and $\mathrm{O}_{2}$ saturation percent were observed in severe cases, compared to control group.

Figure 1 shows sharp elevation $(p<0.0001)$ in the logarithm of serum mir-122 level in severe cases as compared to both normal and mild and moderate groups. In spite of the observed down regulation of mir-499 in serum of severe group, it was statistically nonsignificant, compared to the other two groups.

\section{Echocardiographic Data}

Table 3 and revealed that cases with severe bronchiolitis showed significant decrease $(p<0.0001$ and 0.001 ) in pulmonary At/Et ratio, compared to both normal and mild and moderate groups, respectively. 


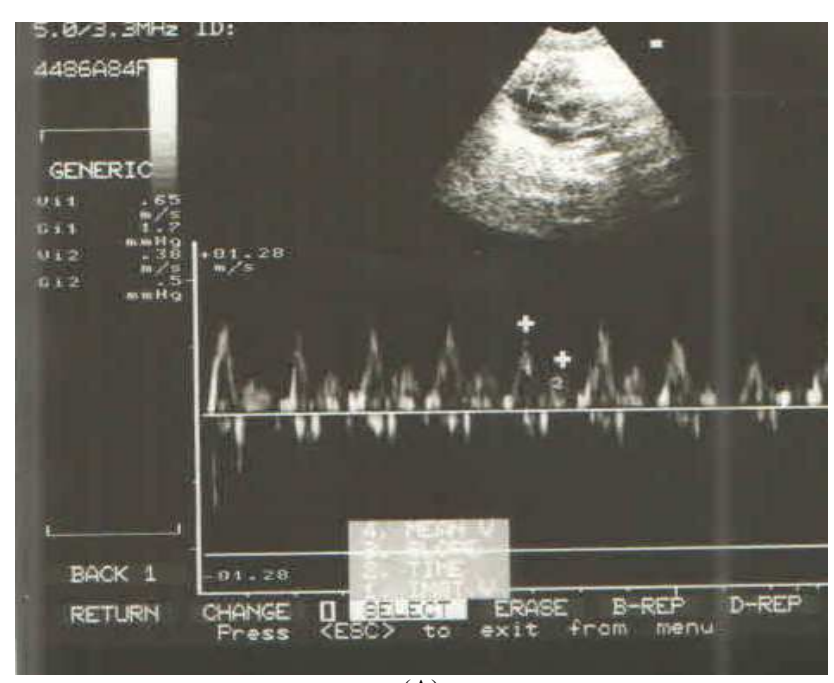

(A)

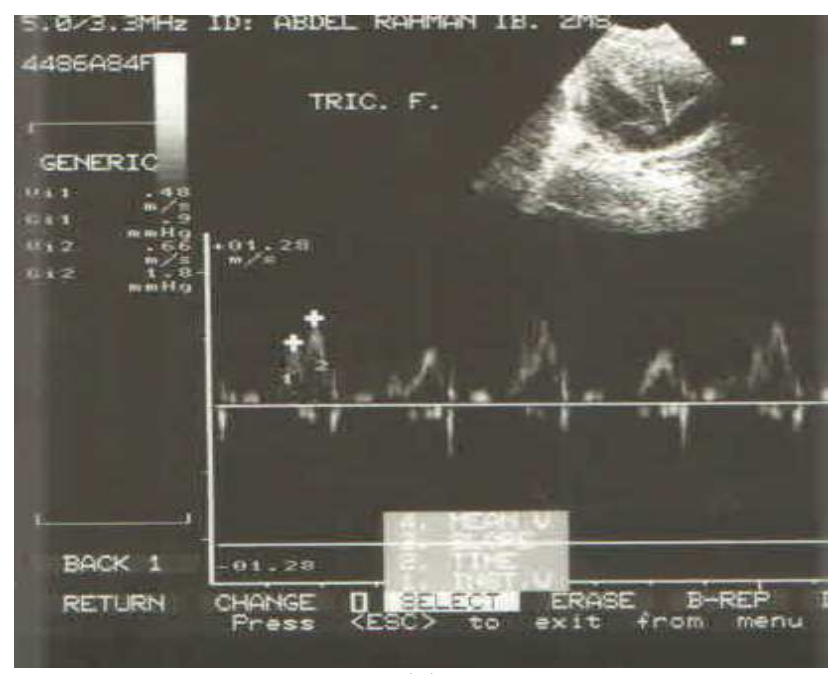

(B)

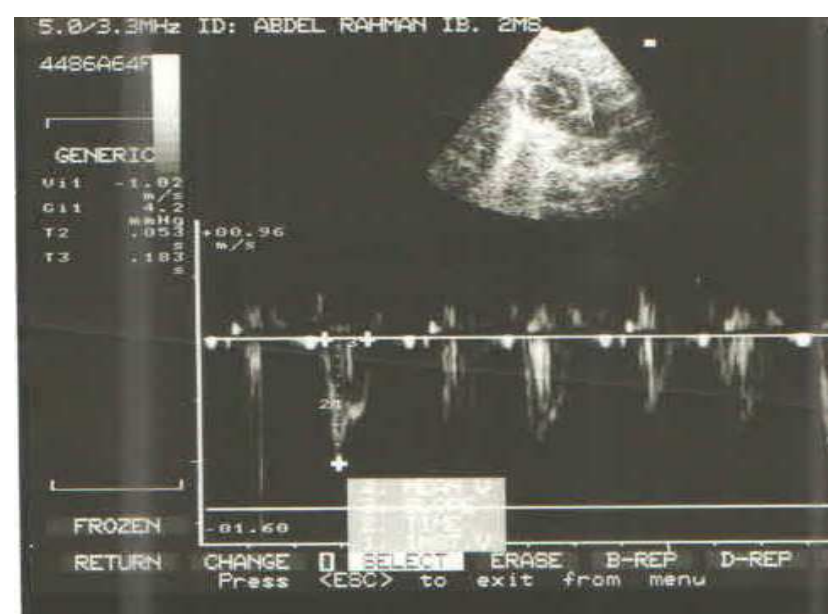

(C)

Fig. 2. Two-dimensional transthoracic echocardiography. (A) Pulsed Doppler echocardiographic through the tricuspid valve of normal case. (B) Pulsed Doppler echocardiographic through the tricuspid valve of severe case showing right ventricular diastolic dysfunction as a result of A wave more than E wave. (C) Pulsed Doppler echocardiographic through the pulmonary valve showing the pulmonary indices (At and Et) 


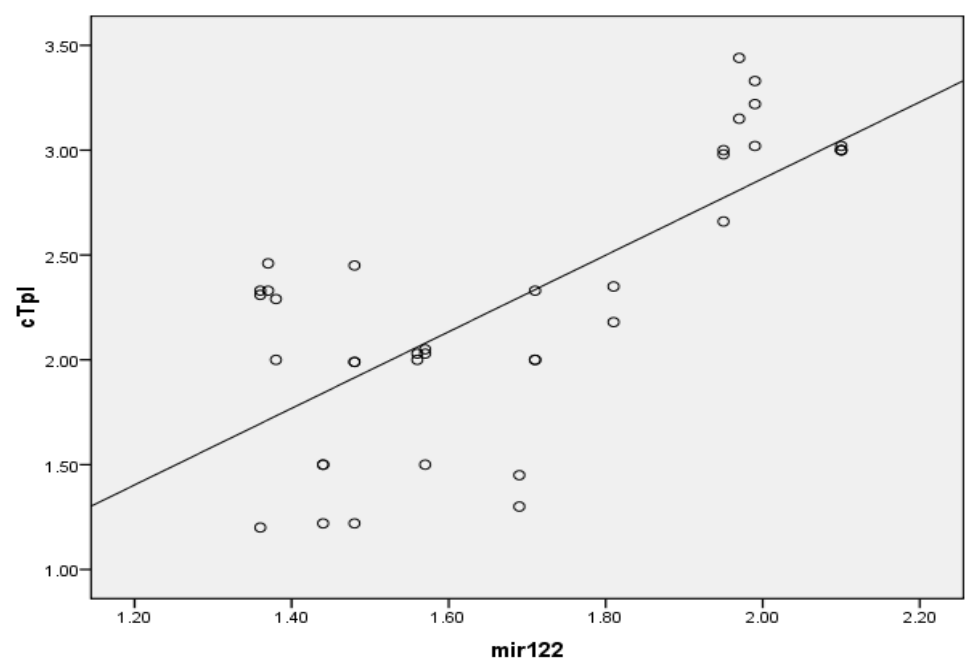

(A)

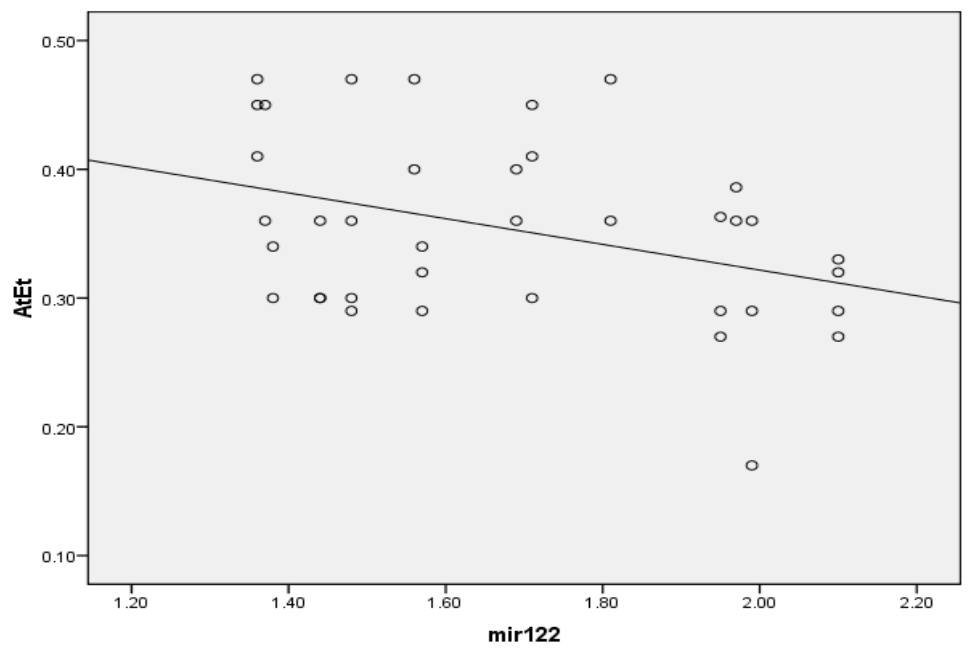

(B)

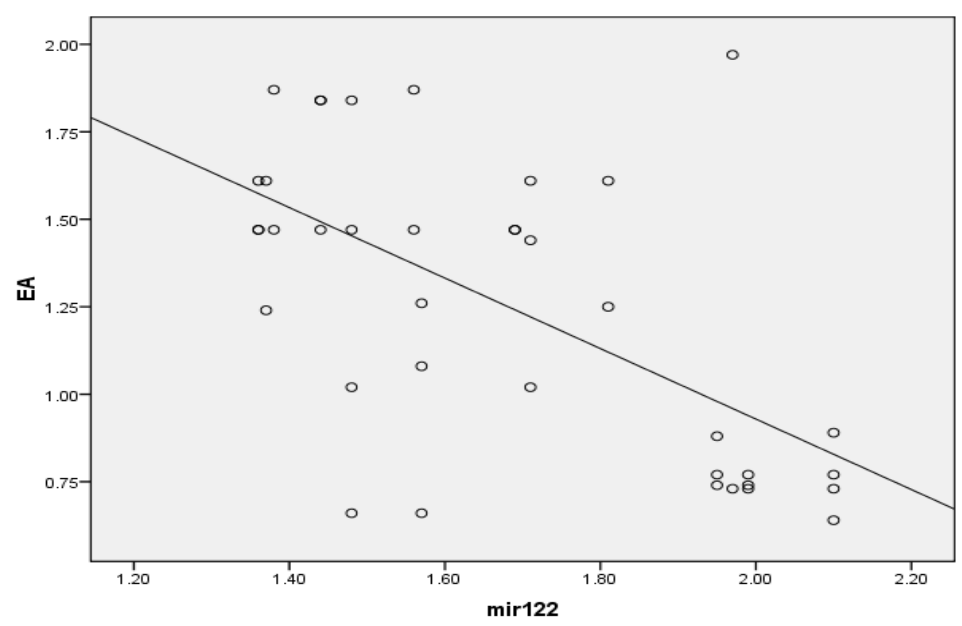

(C)

Fig. 3. Pearson correlations of serum miRNA-122 with (A) cTp I $(r=0.73, p \leq 0.01)$, (B) pulmonary At/Et $(r=-0.37, p \leq 0.02)(C)$ tricuspid $\mathrm{E} / \mathrm{A}(\mathrm{r}=-0.61, \mathrm{p} \leq 0.01)$ 
Table 2. Characteristics of normal children and patients with mild, moderate and severe bronchiolitis (Mean $\pm \mathrm{SE}$ )

\begin{tabular}{|c|c|c|c|}
\hline Groups & Con & Mild and Moderate & Severe \\
\hline Age (mon) & $4.31 \pm 0.59$ & $4.15 \pm 0.44$ & $3.35 \pm 0.41$ \\
\hline Weight (Kg) & $6.54 \pm 0.43$ & $5.97 \pm 0.21$ & $5.90 \pm 0.25$ \\
\hline Respiratory rate $(\mathrm{c} / \mathrm{m})$ & $34.38 \pm 0.81$ & $59.31 \pm 1.95^{\mathrm{a}}$ & $79.38 \pm 1.38^{\mathrm{ab}}$ \\
\hline Heart rate (beat/min) & $116.23 \pm 1.49$ & $120.46 \pm 2.74$ & $135.38 \pm 3.24^{\mathrm{ab}}$ \\
\hline Cyanosis & NO & NO & YES \\
\hline Irritability & NO & YES & YES \\
\hline $\mathrm{pH}$ & $7.40 \pm 0.01$ & $7.37 \pm 0.02$ & $7.28 \pm 0.003^{\mathrm{ab}}$ \\
\hline $\mathrm{pO}_{2}(\mathrm{mmHg})$ & $75.23 \pm 1.03$ & $79.99 \pm 5.64$ & $55.92 \pm 0.1^{\mathrm{ab}}$ \\
\hline $\mathrm{pCO}_{2}(\mathrm{mmHg})$ & $39.92 \pm 1.10$ & $33.51 \pm 2.53^{\mathrm{a}}$ & $51.46 \pm 0.10^{\mathrm{ab}}$ \\
\hline $\mathrm{HCO}_{3}(\mathrm{mmol} / \mathrm{L})$ & $26.00 \pm 0.97$ & $19.63 \pm 0.57^{\mathrm{a}}$ & $19.42 \pm 0.24^{\mathrm{a}}$ \\
\hline $\mathrm{O}_{2}$ sat. $(\%)$ & $93.23 \pm 0.56$ & $94.11 \pm 0.99$ & $85.23 \pm 1.83^{\mathrm{ab}}$ \\
\hline $\mathrm{Hb}(\mathrm{g} / \mathrm{dL})$ & $12.48 \pm 0.33$ & $11.67 \pm 0.54$ & $12.28 \pm 0.54$ \\
\hline RBCs $\left(10^{6}\right.$ cell $\left./ \mathrm{mL}\right)$ & $4.82 \pm 0.19$ & $4.48 \pm 0.26$ & $5.02 \pm 0.10$ \\
\hline WBCs $\left(10^{3}\right.$ cell $\left./ \mathrm{mL}\right)$ & $9.86 \pm 1.28$ & $6.02 \pm 0.21^{\mathrm{a}}$ & $5.48 \pm 0.10^{\mathrm{a}}$ \\
\hline Eosinophyl (\%) & $2.08 \pm 0.24$ & $1.23 \pm 0.26^{\mathrm{a}}$ & $1.08 \pm 0.24^{\mathrm{a}}$ \\
\hline Lymphocyte (\%) & $27.31 \pm 0.87$ & $56.11 \pm 2.13^{\mathrm{a}}$ & $62.00 \pm 1.83^{\mathrm{ab}}$ \\
\hline Monocyte (\%) & $3.92 \pm 0.42$ & $0.54 \pm 0.14^{\mathrm{a}}$ & $1.00 \pm 0.28^{\mathrm{a}}$ \\
\hline Platelet $\left(10^{3}\right.$ cell $\left./ \mathrm{mL}\right)$ & $304.08 \pm 18.78$ & $321.38 \pm 24.17$ & $257.38 \pm 14.35^{\mathrm{b}}$ \\
\hline $\mathrm{CRP}(\mathrm{mg} / \mathrm{L})$ & -ve & -ve & -ve \\
\hline $\mathrm{LDH}(\mathrm{mU} / \mathrm{mL})$ & $1.95 \pm 0.07$ & $2.36 \pm 0.09^{\mathrm{a}}$ & $2.94 \pm 0.02^{\mathrm{ab}}$ \\
\hline CK-MB (ng/mL) & $0.99 \pm 0.07$ & $1.52 \pm 0.07^{\mathrm{a}}$ & $1.73 \pm 0.04^{\mathrm{ab}}$ \\
\hline $\mathrm{cTp}$ I $(\mathrm{ng} / \mathrm{mL})$ & $1.91 \pm 0.14$ & $1.93 \pm 0.09$ & $3.06 \pm 0.05^{\mathrm{ab}}$ \\
\hline
\end{tabular}

a: Significance Vs control group, b: Significance Vs mild and moderate group

Table 3. Echocardiographic measurements of children in different studied groups

\begin{tabular}{llll}
\hline Groups parameters & Con & Mild and Moderate & Severe \\
\hline Pulmonary At/Et & $0.39 \pm 0.02$ & $0.36 \pm 0.02$ & $0.31 \pm 0.02^{\mathrm{ab}}$ \\
Tricuspid E/A & $1.56 \pm 0.06$ & $1.30 \pm 0.11^{\mathrm{a}}$ & $0.85 \pm 0.09^{\mathrm{ab}}$ \\
Mitral E/A & $2.15 \pm 0.07$ & $1.59 \pm 0.04^{\mathrm{a}}$ & $1.89 \pm 0.11^{\mathrm{ab}}$ \\
EF & $61.62 \pm 1.22$ & $59.92 \pm 0.88$ & $61.62 \pm 1.04$ \\
FS & $31.38 \pm 0.40$ & $32.69 \pm 0.68$ & $32.77 \pm 0.58$ \\
\hline
\end{tabular}

a: Significance Vs control group, b: Significance Vs mild and moderate group. EF: Ejection fraction, FS: Fraction shortening

Parallel reduction was also observed in tricuspid and mitral E/A ratios with $p$ values $<0.0001$ and 0.001 for tricuspid and $\mathrm{p}<0.001$ for mitral blood flow compared to both normal and mild and moderate groups, respectively. Mild and moderate cases showed remarkable reduction in tricuspid and mitral blood flow with $\mathrm{p}$ values $<0.049$ and 0.0001 , respectively as compared to normal group (Fig. 2A-C).

Echocardiographic data showed non-significant differences in ejection fraction and fraction shortening in all the studied groups.

To evaluate the significance of increased levels of circulating mir-122, we analyzed whether the level of this miRNA correlated with a set of biochemical and clinical parameters. Figure 3 revealed that the level of circulating mir-122 correlated significantly $(\mathrm{p} \leq 0.01)$ with serum cTp I levels $(r=0.73)$. While, negative correlations were observed between serum mir-122 and both the pulmonary and tricuspid ratios $(\mathrm{r}=-0.37$, $\mathrm{p}<0.02$ and $-0.61, \mathrm{p}<0.01$, respectively).

\section{Discussion}

Acute bronchiolitis produces significant morbidity and mortality worldwide every year. RSV bronchiolitis is the most important cause for admission to the pediatric intensive care unit in infants with lower respiratory tract infection (Eisenhut, 2006). In recent years the importance of extra-pulmonary manifestations of RSV infection has become evident.

Cardiac troponin I (cTp I) is an isoform of a thin filament contractile protein present in high concentrations in the myocardium. It is the only known molecular marker of myocardial injury and is detectable within $6 \mathrm{~h}$ of the damage (Thiru et al., 2000). A number of studies have suggested a possible association between cTp I and myocardial injury in patients with non-cardiac diseases (Khan et al., 1999; ver Elst et al., 2000; Checchia et al., 2000; Ammann et al., 2001). Gurkan et al. (2004) reported that the relationship between cTp I as a marker of cell death and myocardial function suggests that "cell death" may have a role in the 
pathogenesis of myocardial dysfunction in septicaemia. Furthermore, it has been demonstrated in other lung diseases, such as bacterial pneumonia, that severe lung involvement can be accompanied by a significant increase in cTp I and $\mathrm{T}$ concentrations (Weinberg et al., 2002; Labugger et al., 2004).

Increased serum level of cTp I in severe group of the present study is in line with previous studies that demonstrated elevation in cTp I in RSV bronchiolitis (Checchia et al., 2000; Moynihan et al., 2003). Initially, increased levels of cTp I were presumed to be due to myocardial necrosis, as happens in myocardial infarction (Martins et al., 2009). Pulmonary embolism is also a relatively frequent cause of increased plasma troponin (Meyer et al., 2000). In the case of pulmonary embolism, myocardial necrosis is not a prominent phenomenon and right ventricular strain could be the cause of troponin release (Martins et al., 2009). Previous work by Feng et al. (2001) illustrated that preload induces troponin I degradation independently of myocardial ischemia. In addition, Chronic Obstructive Pulmonary Disease (COPD) patients frequently have hypoxia and thus the hypothesis that hypoxia also plays a role in troponin release in COPD patients cannot be ruled out (Martins et al., 2009). Moreover, the RSV may play a direct role in causing heart disease since the virus itself was detected in the myocardial tissue and the occurrence of significant pericardial effusion in children with severe RSV bronchiolitis (Bowles et al., 2003; Eisenhut, 2006; Esposito et al., 2010).

Consequently, elevated serum cTp I in the studied severe cases could be a reflection of hypoxaemia that result from alveolar hypoventilation, indicated by elevated $\mathrm{pCO}_{2}$ and decreased arterial blood oxygenation. In addition, tachycardia and subsequent myocardial strain on the right ventricle associated with pulmonary hypertension, that indicated by decreased At/Et ratio, could be another cause for troponin degradation. Regarding mild to moderate cases, serum cTp I, arterial blood oxygenation and pulmonary At/Et ratio were normal confirming our previous assumption. However, both diseased groups suffered from right and left ventricular diastolic dysfunctions as indicated by decreased E/A ratios for tricuspid and mitral valves, respectively.

To our knowledge, no previous studies have been conducted on circulating miRNA-122 and 499 in infants with acute bronchiolitis. miR-122 is abundantly expressed in the liver and plays a role in Hepatitis $\mathrm{C}$ virus (HCV) replication by binding to sites within the HCV 5 -UTR and stimulating HCV accumulation in vivo (Jopling et al., 2005). Conversely, overexpression of miR-122 blocked replication of Borna disease virus in oligodendralglial cells (Qian et al., 2010) and inhibited HBV expression in hepatoma cells (Qiu et al., 2010).
These data suggest that miR-122 can have contrasting effects on expression of different viruses. In addition, Bruce and Alcorn (2011) studied the differential miRNA expression profile of fetal human type II epithelial cells to RSV infection. Cells were treated in the absence and presence of RSV for two hours. RSV infection resulted in a significant decrease in miRNA-122. The present study revealed that serum level of miRNA-122 was highly expressed in severe bronchiolitis group as compared to both control and mild and moderate cases. While miRNA-499 was not significantly altered in all groups. These results disagree with Bruce and Alcorn (2011). D'Alessandra et al. (2010) reported that acute myocardial infarction up-regulated miRNA-499 plasma levels, both in humans and mice; whereas miRNA-122 was lower than control patients and these miRNAs represent novel biomarkers of cardiac damage.

It has been suggested that miR-122 down-regulates the expression of Cationic Amino Acid Transporter-1 (CAT-1) mRNA (Chang et al., 2004) through binding its 3'-UTR resulting in decreased protein abundance of CAT-1 (Jopling et al., 2006). CAT-1 is a membrane transporter for the essential amino acid arginine, thus supporting important functions, such as synthesis of Nitric Oxide (NO) (Hatzoglou et al., 2004), which acts as an antiviral agent. The study of Tsutsumi et al. (1999) revealed that in spite the up-regulation of the Inducible Nitric Oxide Synthase (iNOS) in RSV-infected respiratory epithelial cells, NO production specific for RSV infection itself could not be detected by nitrite assay. Moreover, Gadish et al. (2010) investigated the Fractional exhaled Nitric Oxide (FeNO) levels in infants during acute RSV bronchiolitis and during convalescence. They found that the FeNO levels were temporarily reduced during acute RSV bronchiolitis and increased during convalescence to normal levels and higher. Thus the up-regulation of miR-122 in the present study may down-regulate the expression of CAT-1 or/and prevent the translation of iNOS mRNA.

According to Pearson's correlation, miRNA-499 did not correlate with cTp I and EF, indicating absence of cardiac damage. Whereas, the positive correlations of miRNA-122 with cTp I, pulmonary hypertension and diastolic dysfunction of the right ventricle indicating presence of cardiac dysfunction.

\section{Conclusion}

Infants with severe acute bronchiolitis suffer from cardiac dysfunction due to hypoxia, cardiac strain and pulmonary hypertension. In spite the up-regulation of serum miRNA-122 in bronchiolitis patients, it cannot be considers as a biomarker. Further research is needed to improve current knowledge of the role of miRNAs particularly 122 in RSV. 


\section{Acknowledgement}

Authors thank Prof. Dr. Hassan S. Abu Saif, Head of Pediatric Cardiology Unit, Pediatric Department, AlHussin University hospital, Faculty of Medicine, AlAzhar University, who performed the echocardiography and explained the data.

\section{Funding Information}

The authors have no support or funding to report.

\section{Author's Contributions}

Mona A. Mohamed: Conceived and designed the study. Performed the experiments and analyzed the data.

Khalid M.S. Zayed: Conceived and designed the study. Selected and followed up the included cases. Authors wrote, read and approved the manuscript.

\section{References}

Ammann, P., T. Fehr, E.I. Minder, C. Günter and O. Bertel, 2001. Elevation of troponin I in sepsis and septic shock. Intensive Care Med., 27: 965-969. PMID: 11497154

Bowles, N.E., J. Ni, D.L. Kearney, M. Pauschinger and H.P. Schultheiss et al., 2003. Detection of viruses in myocardial tissues by polymerase chain reaction. Evidence of adenovirus as a common cause of myocarditis in children and adults. J. Am. Coll. Cardiol., 42: 466-472.

DOI: 10.1016/S0735-1097(03)00648-X

Bravo, V., S. Rosero, C. Ricordi and R.L. Pastori, 2007. Instability of miRNA and cDNAs derivatives in RNA preparations. Biochem. Biophys. Res. Commun., 353: 1052-1055. PMID: 17204243

Brock, S.C., J.R. Goldenring and J.E. Crowe, 2003. Apical recycling systems regulate directional budding of respiratory syncytial virus from polarized epithelial cells. Proc. Nat. Acad. Sci. USA, 100: 15143-15148. DOI: $10.1073 /$ pnas. 2434327100

Bruce, S.R. and J.L. Alcorn, 2011. RSV Induced Changes in miRNA Expression in Lung. In: Human Respiratory Syncytial Virus Infection, Resch, B., (Eds.).

Carrat, F., M. Leruez-Ville, M. Tonnellier, J.L. Baudel and J. Deshayes et al., 2006. A virologic survey of patients admitted to a critical care unit for acute cardiorespiratory failure. Intens. Care Med., 32: 156-159. PMID: 16328219

Chang, J.E.N., D. Marks, C. Sander, A. Lerro and M.A. Buendia et al., 2004. miR-122, a mammalian liverspecific microRNA, is processed from HCR mRNA and may down-regulate the high affinity cationic amino acid transporter CAT-1. RNA Biol., 1: 106-106. PMID: 17179747
Checchia, P.A., H.J. Appel, S. Kahn, F.A. Smith and S.T. Shulman et al., 2000. Myocardial injury in children with respiratory syncytial virus infection. Pediatr. Crit. Care Med., 1: 146-150. PMID: 12813266

Crowe, J.E., 2011. Respiratory Syncytial Virus. In: Nelson Text Book of Pediatrics, Kliegman, R., B. Stanton, J. Geme, N. Schor and R. Behrman (Eds.), Elsevier Saunders, Philadelphia, ISBN-10: 8131232778, pp: 1126-1126.

D’Alessandra, Y., P. Devanna, F. Limana, S. Straino and A. Di Carlo et al., 2010. Circulating microRNAs are new and sensitive biomarkers of myocardial infarction. Eur. Heart J., 31: 2765-2773. DOI: $10.1093 /$ eurheartj/ehq167

Eisenhut, M., 2006. Extrapulmonary manifestations of severe respiratory syncytial virus infection. Crit. Care, 10: R107-R107. DOI: 10.1186/cc4984

Esposito, S., P. Salice, S. Bosis, S. Ghiglia and E. Tremolati et al., 2010. Altered cardiac rhythm in infants with bronchiolitis and respiratory syncytial virus infection. BMC Infectious Diseases, 10: 305-305. PMID: 20969802

Feng, J., B.J. Schaus, J.A. Fallavollita, T.C. Lee and J.M. Canty, 2001. Preload induces troponin I degradation independently of myocardial ischemia. Circulation, 103: 2035-2037. DOI: 10.1161/01.CIR.103.16.2035

Gadish, T., R. Soferman, T. Merimovitch, E. Fireman and Y. Sivan, 2010. Exhaled nitric oxide in acute respiratory syncytial virus bronchiolitis. Arch. Pediatr. Adolesc. Med., 164: 727-731. DOI: 10.1001/archpediatrics.2010.128

Gidlöf, O., P. Andersson, J. van der Pals, M. Götberg and D. Erlinge, 2011. Cardiospecific microRNA plasma levels correlate with troponin and cardiac function in patients with ST elevation myocardial infarction, are selectively dependent on renal elimination and can be detected in urine samples. Cardiology, 118: 217-226. DOI: 10.1159/000328869

Gurkan, F., A. Alkaya, A. Ece, K. Haspolat and M. Bosnak et al., 2004. Cardiac troponin-I as a marker of myocardial dysfunction in children with septic shock. Swiss Med. Wkly., 134: 593-596. PMID: 15592951

Hatzoglou, M., J. Fernandez, I. Yaman and E. Closs, 2004. Regulation of cationic amino acid transport: the story of the CAT-1 transporter. Annu. Rev. Nutr., 24: 377-399.

DOI: 10.1146/annurev.nutr.23.011702.073120

Humphreys, D.T., B.J. Westman, D.I. Martin and T. Preiss, 2005. MicroRNAs control translation initiation by inhibiting eukaryotic initiation factor 4E/cap and poly(A) tail function. Proc. Nat. Acad. Sci. USA, 102: 16961-16966. DOI: $10.1073 /$ pnas. 0506482102 
Jopling, C.L., M. Yi, A.M. Lancaster, S.M. Lemon and P. Sarnow, 2005. Modulation of hepatitis C virus RNA abundance by a liver-specific MicroRNA. Science, 309: 1577-1581. PMID: 16141076

Jopling, C.L., K.L. Norman and P. Sarnow, 2006. Positive and negative modulation of viral and cellular mRNAs by liver-specific microRNA miR122. Cold Spring Harb. Symp. Quant. Biol., 71: 369-376. DOI: $10.1101 /$ sqb.2006.71.022

Khan, I.A., A. Tun, N. Wattanasauwan, M.T. Win and T.A. Hla et al., 1999. Elevation of serum cardiac troponin I in noncardiac and cardiac diseases other than acute coronary syndromes. Am. J. Emerg. Med., 17: 225-229. PMID: 10337875

Labugger, R., L. Organ, C. Collier, D. Atar and J.E. Van Eyk, 2004. Extensive troponin I and T modification detected in serum from patients with acute myocardial infarction. Circulation, 102: 1221-1226. DOI: 10.1161/01.CIR.102.11.1221

Lakhanpaul, M., R. MacFaul, U. Werneke, K. Armon and P. Hemingway et al., 2009. An evidence-based guideline for children presenting with acute breathing difficulty. Emerg. Med. J., 26: 850-853. PMID: 19934124

Martins, C.S., M.J.O. Rodrigues, V.P. Miranda and J.P.L. Nunes, 2009. Prognostic value of cardiac troponin I in patients with COPD acute exacerbation. J. Med., 67: 341-349. PMID: 19915228

Meyer, T., L. Binder, N. Hruska, H. Luthe and A.B. Buchwald, 2000. Cardiac troponin I elevation in acute pulmonary embolism is associated with right ventricular dysfunction. J. Am. Coll. Cardiol., 36: 1632-1636. DOI: 10.1016/S0735-1097(00)00905-0

Moynihan, J.A., L. Brown, R. Sehra and P.A. Checchia, 2003. Cardiac troponin I as a predictor of respiratory failure in children hospitalized with Respiratory Syncytial Virus (RSV) infections: A pilot study. Am. J. Emerg. Med., 21: 479-482. PMID: 14574656

Oll, M., C. Baumann, T.E. Behbahani, A. von Ruecker and S.C. Müller et al., 2012. Identification of prostaglandin receptors in human ureters. BMC Urology, 12: 35-35. DOI: 10.1186/1471-2490-12-35
Qian, J., A. Zhai, W. Song, Y. Fu and X. Chen et al., 2010. Modulation of miR-122 on persistently Borna disease virus infected human oligodendroglial cells. Antiviral Res., 87: 249-256. PMID: 20561966

Qiu, L., H. Fan, B. Zhao, Y. Wang and Y. Ju et al., 2010. miR-122-induced down-regulation of HO-1 negatively affects miR-122-mediated suppression of HBV. Biochem. Biophys. Res. Commun., 398: 771-777. PMID: 20633528

Scarfone, R.J., 2005. Controversies in the treatment of bronchiolitis. Curr. Opin. Pediatr., 17: 62-66. PMID: 15659966

Small, E.M. and E.N. Olson, 2011. Pervasive roles of microRNAs in cardiovascular biology. Nature, 469: 336-342. DOI: 10.1038/nature09783

Thiru, Y., N. Pathan, S. Bignall, P. Habibi and M. Levin, 2000. A myocardial cytotoxic process in involved in the cardiac dysfunction of meningococcal septic shock. Crit. Care Med., 28: 2979-2983. PMDI: 10966282

Thorburn, K. and C.A. Hart, 2006. Think outside the box: Extrapulmonary manifestations of severe respiratory syncytial virus infection. Crit. Care, 10: 159-159. DOI: 10.1186/cc5012

Tsutsumi, H., R. Takeuchi, M. Ohsaki, K. Seki and S. Chiba, 1999. Respiratory syncytial virus infection of human respiratory epithelial cells enhances inducible nitric oxide synthase gene expression. J. Leukoc. Biol., 66: 99-104. PMID: 10410996

ver Elst, K.M., H.D. Spapen, D.N. Nguyen, C. Garbar and L.P. Huyghens et al., 2000. Cardiac troponins I and $\mathrm{T}$ are biological markers of left ventricular dysfunction in septic shock. Clin. Chem., 46: 650-657.

Weinberg, I., T. Cukierman and T. Chajek-Shaul, 2002. Troponin $\mathrm{T}$ elevation in lobar lung disease. Postgrad. Med. J., 78: 244-245. PMID: 11930030 